\section{Desafíos de la salud pública bucal en el Perú - análisis crítico}

Vallejos-Ragas R. Desafíos de la salud pública bucal en el Perú - análisis crítico. Rev Estomatol Herediana. 2009; 19(1):66-69.
Raúl Vallejos Ragas

Instituto de Desarrollo Odontológico - IDEO

Correspondencia

Raúl Vallejos Ragas

Calle Emilio Althaus 121 of. 601- Lima 14, Perú

Teléfono: 4702575

Teléfono: 4702575

\section{Introducción}

Los logros en el Perú, que actualmente llaman la atención a la comunidad internacional, están determinados por indicadores macroeconómicos positivos ${ }^{\mathrm{a}}$. Estos resultados se asocian a la continuidad desde 1990, de políticas económicas neoliberales por parte del estado. Sin embargo, estas políticas han generando efectos negativos en el sector salud, los que se suman a problemas ya existentes en este campo.

Dentro de la salud pública peruana, la salud bucal y la profesión odontológica, atraviesan una etapa de estancamiento, probablemente por la influencia de dos factores 1) el desinterés de las instituciones públicas en el tema bucal. Siendo una evidencia la variación del número de odontólogos en este sector entre 1996 y el 2002, donde los odontólogos disminuyeron en $25 \%$ (0,83/10000 hab); contrariamente, en el mismo periodo los médicos se incrementaron en $11.42 \%$, las enfermeras en $35,12 \%$ y las obstetrices en $53,73 \%$ (1); y 2) la escasa respuesta de los odontólogos y sus instituciones en propuestas y acciones que mejoren el estado de salud bucal de la población y afronten la problemática de la profesión.

Bajo una perspectiva contemporánea, la identificación de tres dimensiones que engloban la problemática en mención, pueden ser considerados como retos o desafíos que los profesionales y organizaciones vinculados a la salud bucal tendrán que enfrentar. Para esto, se hace necesario profundizar en el origen e implicancias de cada uno de estos desafíos.

\section{Desafío 1: Políticas neo liberales y ausencia de planificación}

En noviembre de 1989 y producto de una conferencia del Institute for International Economics, es presentado el denominado "Consenso de Washington". Dicho documento señala un listado de reformas económicas, que los países latinoamericanos deberían aplicar ante la crisis económica de esa época. Entre estas medidas, resaltaba la desregulación de diversas actividades, como la educación, esperando que la competencia y las reglas del mercado sean las reguladoras (2).

El Perú, desde inicios de los 90, comienza la implementación de estas recomendaciones. Las principales medidas que afectan directa e indirectamente al sector salud son: a) desactivación del Instituto Nacional de Planificación y b) la norma legal de Promoción de la inversión privada en la Educación $(3,4)$. La autonomía universitaria que permite la creación de nuevas facultades, apuntaló las condiciones para un total liberalismo.

Los efectos percibidos en el campo de la salud pública bucal, producto de estas normas, se describen en la Tabla 1.

El problema del incremento de facultades es muy similar al de otras profesiones del sector salud. No obstante, la profesión de Medicina Humana, es la única que ha intentado controlarlo, mediante normas legales que detengan y regulen la formación medica (5), siendo estas medidas aún insuficientes. No obstante, la profesión odontológica aún no ha tomado acciones que reviertan esta situación.

\section{Desafío 2: Sistema de Salud en el Perú}

En el año 2000, la Organización Mundial de la Salud (OMS) publicó un informe sobre el desempeño de 191 sistemas de salud de igual número de países (6). El Perú ocupó el puesto 129 (el menos destacado en Latinoamérica). El porque ocupamos ese puesto, podría explicarse por la forma de construcción del "sistema"b.

El sistema de salud peruano, se define como segmentadoc. Este es el producto de una construcción incremental y no planificada, a consecuencia de iniciativas que respondían a problemas o demandas de distintos grupos poblacionales ${ }^{\mathrm{d}}$.

${ }^{a}$ Crecimiento del PBI en 6\% anual en los últimos seis años, inflación del 2.8\% anual y aumento de las exportaciones a una tasa del 24\% por año.

${ }^{\mathrm{b}}$ Conjunto de partes o elementos organizadas y relacionadas que interactúan entre sí para lograr un objetivo

cParticipan dos sub sectores a) Subsector Público, formado por el Ministerio de Salud, la Seguridad Social, Sanidad de Fuerzas Armadas y Policía Nacional y b) Subsector No

Público, conformado por clínicas y consultorios privados, organizaciones no gubernamentales, servicios de origen religioso, gobiernos locales, etc.

dObreros, empleados, militares, policías, pescadores, etc. 
Tabla 1. Efectos del libre mercado en la salud pública bucal*

\begin{tabular}{|c|c|c|}
\hline Área & Educación & Salud \\
\hline $\begin{array}{l}\text { Competencias } \\
\text { por mercado }\end{array}$ & $\begin{array}{l}\text { - Competencia entre facul- } \\
\text { tades por captar nuevos } \\
\text { postulantes. } \\
\text { - Se facilita el proceso de } \\
\text { ingreso a universidades. } \\
\text { - Se inician procesos de } \\
\text { acreditación de faculta- } \\
\text { des de odontología. }\end{array}$ & $\begin{array}{l}\text { - Competencia de los } \\
\text { servicios de salud } \\
\text { públicos y privados por } \\
\text { captar potenciales } \\
\text { “clientes”. No se } \\
\text { incluye a la Seguridad } \\
\text { Social. }\end{array}$ \\
\hline $\begin{array}{l}\text { Recursos } \\
\text { Humanos }\end{array}$ & $\begin{array}{l}\text { - Se desconoce el número } \\
\text { de profesionales que } \\
\text { requiere el país. } \\
\text { - Incremento de } 10 \text { a } 32 \\
\text { facultades de odontología } \\
\text { entre } 1990 \text { y el } 2007 . \\
\text { - Incremento del } 400 \text { a } \\
\text { mas de } 1000 \\
\text { odontólogos egresados } \\
\text { por año (desde 1990). }\end{array}$ & $\begin{array}{l}\text { - Se desconoce el } \\
\text { número de profesiona- } \\
\text { les que requiere el } \\
\text { sector público. } \\
\text { - Escasa contratación de } \\
\text { odontólogos en el } \\
\text { sector publico. } \\
\text { - Sobre oferta de } \\
\text { odontólogos en sector } \\
\text { privado. } \\
\text { - Distribución de odontó- } \\
\text { logos en regiones de } \\
\text { mejor condición econó- } \\
\text { mica. } \\
\text { - Incremento de la } \\
\text { migración por parte de } \\
\text { odontólogos. }\end{array}$ \\
\hline $\begin{array}{l}\text { Perfil } \\
\text { Profesional }\end{array}$ & $\begin{array}{l}\text { - Se favorecen postgrados } \\
\text { en especialidades de alta } \\
\text { rentabilidad (Estética, } \\
\text { Ortodoncia, Implantes). } \\
\text { - Escasa oferta de } \\
\text { postgrado en Salud } \\
\text { Pública. }\end{array}$ & $\begin{array}{l}\text { - Escaso impacto de las } \\
\text { intervenciones en salud } \\
\text { bucal. }\end{array}$ \\
\hline
\end{tabular}

*Fuente propia

Esto ocasionó la creación de una amplia gama de organizaciones e instituciones con fines diversos, que en conjunto han formado "el sistema de salud". Sin embargo, como este proceso respondía a propuestas políticas y no ha una visión sistémica, sectores de la población han quedado marginados de la atención de salud (7).

Esta característica, encuentra sus primeros obstáculos en concertar acciones comunes, para la implementación de las políticas de salud. Con el fin de enmendar dicho problema, el estado conformó el Sistema Nacional Coordinado y Descentralizado de Salude (8).

La salud bucal, dentro de este sistema es considerada como la Estrategia Sanitaria Nacional de Salud Bucal ${ }^{f}$ (9). El coordinador de esta estrategia (del Ministerio de Salud), tiene como misión lograr que los subsectores del sistema relacionados a la salud bucal, se articulen (organizacional, funcional, y económicamente) en función de una estrategia propuesta. La ausencia de un presupuesto determinado para financiar la implementación de sus actividades y los distintos mandatos de cada organización, conllevan a que solo el Ministerio de Salud (MINSA), en algunos casos acompañado de otras organizaciones actúen en la aplicación de la estrategia y no el sistema de salud en forma "coordinada".

Ante esta situación la estrategia tendrá un limitado margen de acción, y por consiguiente un relativo impacto en sus intervenciones, postergándose así la respuesta necesaria que la población requiere. Por lo tanto, es necesario analizar, evaluar y proponer un modelo que garantice las eficiencias de las acciones ante tal escenario.

\section{Desafío 3: Débil institucionali- dad de las organizaciones odontológicas}

La creación de una organización responde frecuentemente al interés de un grupo de personas, que han identificado problemas comunes y consideran que organizadamente pueden atenderla. En el campo odontológico, se cuentan, 25 sociedades científicas, 32 facultades, escuelas o filiales odontológicas y 23 colegios odontológicos regionales, faltando considerar organizaciones civiles y comerciales, entre otras $(1,10)$.

Agencias internacionales como la OMS/OPS (11) y el Banco Mundial (12), señalan que las organizaciones en Latinoamérica y en el Perú respectivamente, cuentan con una baja capacidad institucional, lo que

${ }^{e}$ Finalidad de coordinar los procesos relacionados a la política nacional de salud

${ }^{\mathrm{f}}$ A cargo de un Coordinador Nacional. Dicho coordinador tiene como función diseñar, planificar, programar, monitorear, supervisar y evaluar la implementación y ejecución de la Estrategia Nacional, así como su articulación intra e intersectorial. 
Tabla 2. Actividades de organizaciones relacionadas a la Odontología*

\begin{tabular}{|c|c|c|c|}
\hline Sectores & Organizaciones & Acciones & Características \\
\hline \multirow[t]{3}{*}{$\begin{array}{l}\text { Sector } \\
\text { Público }\end{array}$} & $\begin{array}{l}\text { Ministerio de } \\
\text { Salud }\end{array}$ & $\begin{array}{l}\text { Tres Estudios } \\
\text { epidemiológicos } \\
\text { nacionales en } \\
\text { salud bucal. }\end{array}$ & $\begin{array}{l}\text { Sólo } 1 \text { publicado. } \\
\text { El publicado con } \\
\text { problemas } \\
\text { técnicos que } \\
\text { ponen en duda su } \\
\text { validez. }\end{array}$ \\
\hline & $\begin{array}{l}\text { Seguridad Social } \\
\text { - Essalud }\end{array}$ & $\begin{array}{l}\text { Bajo número } \\
\text { Odontólogos. }\end{array}$ & $\begin{array}{l}0,83 \text { odontólogos } \\
\text { por cada } 10000 \\
\text { asegurados. }\end{array}$ \\
\hline & $\begin{array}{l}\text { Gobiernos } \\
\text { Regionales }\end{array}$ & $\begin{array}{l}\text { Políticas en Salud } \\
\text { bucal. }\end{array}$ & $\begin{array}{l}\text { Sólo un gobierno } \\
\text { ha conformado un } \\
\text { comité en salud } \\
\text { bucal. }\end{array}$ \\
\hline \multirow[t]{4}{*}{$\begin{array}{l}\text { Asociacio } \\
\text { nes } \\
\text { privadas } \\
\text { y } \\
\text { universit } \\
\text { arias }\end{array}$} & $\begin{array}{l}\text { Colegio } \\
\text { Odontológico }\end{array}$ & $\begin{array}{l}\text { Políticas y } \\
\text { acciones } \\
\text { organizacionales. } \\
\text { Economía } \\
\text { organizacional. }\end{array}$ & $\begin{array}{l}\text { Falta de continui- } \\
\text { dad asociada a } \\
\text { cambio de nuevas } \\
\text { directivas. } \\
\text { Conflictos relacio- } \\
\text { nados al manejo } \\
\text { económico. }\end{array}$ \\
\hline & $\begin{array}{l}\text { Sociedades } \\
\text { Científicas }\end{array}$ & $\begin{array}{l}\text { Producción } \\
\text { científica. }\end{array}$ & $\begin{array}{l}\text { Escasa producción } \\
\text { científica. }\end{array}$ \\
\hline & $\begin{array}{l}\text { Facultades } \\
\text { Odontología }\end{array}$ & $\begin{array}{l}\text { Formación } \\
\text { Odontólogos. }\end{array}$ & $\begin{array}{l}\text { Incremento del } \\
\text { número de } \\
\text { egresados en mas } \\
\text { del } 150 \% \text { por año. }\end{array}$ \\
\hline & $\begin{array}{l}\text { Asociación } \\
\text { Peruana } \\
\text { Facultades } \\
\text { Odontología } \\
\text { (ASPEFO) }\end{array}$ & $\begin{array}{lrr}\begin{array}{l}\text { Congregar } \\
\text { totalidad }\end{array} & \text { la } \\
\text { facultades } & & \text { y } \\
\text { escuelas } & & \text { de } \\
\text { odontología. } & \end{array}$ & $\begin{array}{l}\text { No se ha logrado } \\
\text { ninguna acción } \\
\text { concreta ante la } \\
\text { problemática } \\
\text { vigente. }\end{array}$ \\
\hline
\end{tabular}

\footnotetext{
*Fuente propia
}

no le permite el desarrollo de políticas y planes. Las organizaciones odontológicas, no están ajenas a esta característica regional.

Con el fin de evaluar la institucionalidad de una organización, se utiliza como indicador el desempeño organizacional, tal como se describió en el desafío 2, con relación al sistema de salud.

La evaluación de organizaciones vinculadas a la odontología aún esta pendiente, sin embargo, se perciben señales negativas con relación a su desempeño.

El fortalecimiento institucional se ha convertido en la actualidad en un proceso necesario, si una organización quiere desarrollarse y mantener una línea de desarrollo sostenida.

Probablemente las mayores barreras surjan de aspectos culturales y de la débil conducta ciudadana, traducido en el constante renacimiento de las organizaciones, con cada nueva gestión.

\section{Reflexión Final}

La diversidad de problemas descritos y asociados a la salud pública bucal, vislumbra un escenario negativo y un futuro poco alentador. Sin embargo, la crítica situación nos obliga a grandes cambios, que deberán empezar probablemente por identificar y reconocer nuestras debilidades profesionales y organizacionales, a partir de lo cual podamos construir propuestas que estén a la altura de los desafíos antes descritos.

\section{Referencias bibliográficas}

1. Vallejos R, Campos R. Formación de Odontólogos y Libre Mercado. Efectos de la ausencia de planificación y regulación. En proceso de publicación

2. Mesa-Lago C. Desarrollo social, reforma del Estado y de la seguridad social, al umbral del siglo XXI. Serie Políticas Sociales $N^{\circ} 36$. CEPAL. Enero 2000

3. Decreto Ley 25548 - Creación de la Comisión de disolución y transferencia del Instituto Nacional de Planificación (INP). Junio 1992

4. Decreto Legislativo 882 Promoción de la Inversión Privada en la educación. 1996

5. Ley 27154. Ley que Institucionaliza la Acreditación de facultades y escuelas de Medicina. Julio 1999.

6. Organización Mundial de la Salud (OMS). Informe sobre la Salud en el Mundo 2000 - Mejorar el desempeño de los sistemas de Salud. Ginebra. Suiza.

7. Organización Panamericana de la Salud (OPS). Salud en las Américas, 2007. Volumen II Países.

8. Ley 27913. Sistema Nacional Coordinado y Descentralizado de salud - SNCDS. 13 de Agosto de 2002

9. Resolución Ministerial $N^{\circ} 649$ 2007/MINSA. Estrategia Sanitaria Nacional de Salud Bucal. 8 de Agosto del 2007. 10. Colegio Odontológico del Perú. 
[web Internet]. 2008 Nov. 11.OMS/OPS. La cooperación [citado 2008 Nov. 30]. Disponible en: http://www.cop .org.pe/index.php?option=com _content \& task=view \&id= 57\&Itemid=128. centrada en los países y el desarrollo nacional de la salud. 46 Consejo Directivo/57 Sesión del comité regional. Setiembre 2005.
12.Burdescu R, Frank J, Newman J L. Quesada J M, Rojas F. Gobernabilidad e instituciones en Perú la Oportunidad de un país diferente. Banco Mundial. Lima 2006. 